\title{
UTILIZAÇÃO DE ANTIMICROBIANO PRODUZIDO POR BACTERIA NA ESTERILIZAÇÃO DE FRASCOS DE USO LABORATORIAL.
}

Roters, Jessica Maria Coutinho (jroters@yahoo.com.br) - Universidade Federal de Minas Gerais, UFMG.

Evanguedes, Kalapothakis (kalapothakis@gmail.com) - Universidade Federal de Minas Gerais, UFMG.

\section{RESUMO}

Significativa variedade de bactérias produz lipases que apresentam potencial para aplicações comerciais devido sua estabilidade, seletividade e larga especificidade por substratos. O objetivo deste trabalho foi explorar a ação antimicrobiana de um composto natural obtido a partir da ação enzimática da bactéria A43.6 em óleo de girassol, visando a ação esterilizante deste produto em embalagens PET de uso laboratorial, buscando alternativas mais acessíveis aos procedimentos de esterilização habituais (autoclave e radiação), visto que em alguns ambientes esses equipamentos são inacessíveis. O composto PHT é produzido a partir do processo de incubação do óleo comercial de girassol com lipase, diluída em tampão ou água, temperatura entre 20 a $50^{\circ} \mathrm{C}$, o óleo é modificado através da ação da lipase. O resultado do processo de produção resulta em duas fases, a fase aquosa (FA) e fase oleosa (FO); ambas foram usadas. A FO foi misturada com álcool 70\% nas diluições 1\%, 5\%, $10 \%, 15 \%$ e $20 \%$ para esterilizar as embalagens PET. Os resultados mostraram que o produto diminui os índices de contaminação quando comparados ao controle negativo (frascos tratados com água) e positivo (frascos tratados com álcool 70\%). Os testes indicaram que o uso do antimicrobiano é eficaz, abrindo novas perspectivas mercadológicas.

Palavras chave: esterilização; lipase; antimicrobiano. 


\section{INTRODUÇÃO}

Bactérias são microrganismos unicelulares facilmente encontradas no ambiente e, devido à alta diversidade de espécies e fácil adaptação a diferentes habitats, podem ser usadas em benefício do homem em processos de produção de alimentos, remédios entre outros. Por volta de 2 mil anos a.C. os egípcios já usavam estes microrganismos para fabricação de alimentos e bebidas. Esses processos evoluíram desde então, culminando na biotecnologia, ou seja, a aplicação de organismos e ou de seus derivados e de sistemas biológicos na produção de bens e serviços é chamado de biotecnologia e sua aplicação até início do século XX na indústria de alimentos se restringia à produção de pães, queijos, álcool, vinagre e iogurte (TORTORA et al., 2012)

Desta forma, com o advento da biotecnologia, e descobertas de novas técnicas, o interesse por processos biotecnológicos associado a microrganismos é cada vez maior, isso porque existem muitos progressos nas técnicas de produção de alimentos e bioingredientes por fermentação, por processos enzimáticos e por engenharia genética a partir de sistemas biológicos derivados do DNA recombinante (rDNA) (BELÉM, 2000).

Um grupo de substâncias orgânicas que desperta grande interesse biotecnológico são as enzimas, produzidas por microrganismos animais e vegetais e utilizadas em variadas aplicações industriais (RODRIGUES, 2009). O mercado industrial de enzimas cresce vertiginosamente devido à implantação de novas tecnologias de produção, no uso da engenharia genética na produção e ao surgimento de novos campos de aplicação. Devido às numerosas fusões entre as indústrias enzimáticas, somente em 2011 o mercado das enzimas foram avaliadas em US\$1,2 bilhão, e este número subiu para US\$ 2,2 bilhões em 2016 (ENZYME MARKET, 2016). A capacidade catalítica das enzimas as torna adequadas para aplicações industriais, como indústria farmacêutica, alimentar e agropecuária, e isso tornou-se a premissa de novos sistemas enzimáticos que não puderam ser obtidos das fontes animais e vegetais, exigindo novas pesquisas, visto que os métodos de fermentação para produção de enzimas por microrganismos não têm assegurado um suprimento potencialmente ilimitado (LIN et al., 2005). A utilização de compostos naturais com atividade antimicrobiana vem recebendo atenção atualmente. Porém, a sua aplicação prática é limitada devido às interferências no sabor e possível interação com 
ingredientes dos alimentos. Outro problema é o desenvolvimento de estirpes resistentes aos antibióticos, o que também impede uma maior utilização desses agentes na indústria de alimentos. Diante dessas questões, é necessário o desenvolvimento de antimicrobianos cada vez mais naturais, estáveis, com baixa toxicidade para consumidores (humanos e animais) e viáveis para aplicação em um sistema de conservação de alimentos (ARAUJO et al., 2015).

Na patente WO 2014097218 A1 - “Óleo de girassol (Helianthus annuus) modificado enzimaticamente, processo de obtenção e uso dos seus derivados como antimicrobianos", os autores propuseram uma alternativa para a conservação de alimentos, utilizando o óleo de girassol modificado enzimaticamente com lipases, a fim de obter agentes antimicrobianos para conservação de alimentos, cosméticos, medicamentos, entre outros uso, como agente de esterilização (KALAPOTHAKIS \& VICTORIA, 2012). O composto antimicrobiano PHT apresenta características inovadoras, é sustentável, produção não demanda muitos custos e apresenta vantagens para indústrias e consumidores; além de ser um produto natural, é um antimicrobiano com amplo espectro de ação e seguro para o consumo. Desde a sua produção até o consumidor final, o composto apresenta vantagens em relação aos conservantes químicos, dentre elas: obtenção ambientalmente mais limpa; fácil manejo, armazenagem e transporte; valor no mercado competitivo; amplo espectro de ação contra patógenos; agente natural com toxicidade reduzida. A identificação de novas fontes de lipases de bactérias isoladas do meio ambiente possibilita o desenvolvimento de novos sistemas enzimáticos e, consequentemente, de novos produtos. Percebendo a importância dessa questão, pesquisadores de uma empresa testaram diferentes bactérias e descobriram uma na região de Belo Horizonte - denominada A43.6 - que produz lipase (s).

Esse microrganismo produtor de lipase, previamente isolado e caracterizado pela empresa, foi utilizado na produção das enzimas; enzimas estas presentes no composto PHT.

O composto antimicrobiano foi produzido utilizando a lipase sintetizada pela bactéria A43.6 misturado a uma solução contendo água, óleo e tampão mantidos a temperatura ambiente.

A conscientização e a preocupação com o meio ambiente crescem gradativamente a cada dia. É sabido que após a Revolução industrial, o consumismo desenfreado e o descarte dos produtos são intensos e isso faz com que o ambiente seja contaminado por resíduos. A partir da 
década de 90, organizações mundiais começaram a se preocupar com essas questões e a disseminar o conceito de reciclagem, reaproveitamento, entre outros; e atualmente, há um incentivo na criação de fontes reversas de distribuição que minimizem e solucionem o problema da quantidade de produtos descartados no meio ambiente. Desta forma, a Logística Reversa apresenta-se como uma ferramenta para o crescimento da sustentabilidade (ABIPET, 2012).

A embalagem PET (Poli Tereftalato de Etileno) é um poliéster, polímero termoplástico, e configura-se como o melhor e mais resistente plástico para fabricação de garrafas, frascos e embalagens para refrigerantes, águas, sucos, óleos comestíveis, medicamentos, cosméticos, produtos de higiene e limpeza, destilados, isotônicos, cervejas, entre vários outros (ABIPET, 2012). Desta forma, tem mostrado ser o recipiente ideal para a indústria de bebidas em todo o mundo, reduzindo custos de transporte e produção, evitando desperdícios em todas as fases de produção e distribuição. Além de ser utilizado em outras esferas, como indústrias de alimentos, farmacêuticas e cosmética. São muitos os métodos de esterilização, mas muitas vezes o PET é danificado, por exemplo, algumas embalagens PETs podem perder suas características quando colocados em autoclave.

Antimicrobianos, que são agentes químicos que matam ou inibem o crescimento de microrganismos, impedem a proliferação dos microrganismos em equipamentos, superfícies, entre outros. A contaminação indesejada por um microrganismo pode desencadear problemas a saúde pública, afetar processos industriais, levar a contaminação cruzada em pessoas, e causar problemas nos laboratórios. Com o aparecimento de novos microrganismos resistentes a antibióticos e todas as implicações que isso gera, cria-se a necessidade de novas estratégias para controle e eliminação dessas estirpes. Nesse contexto, a estratégia proposta no presente estudo buscará estabelecer um protocolo utilizando o PHT A43.6 para esterilizar frascos. O composto PHT 43.6 é um antimicrobiano natural, produzido pela ação enzimática de uma bactéria sobre o óleo de girassol comumente utilizado na alimentação humana. $\mathrm{O}$ antimicrobiano tem vantagens por ser sintetizado a partir de um microrganismo; sua produção não envolve equipamentos sofisticados; é fácil de preparar e o custo é baixo. Os resultados em testes anteriores mostraram que o PHT 43.6 tem efetiva atividade antimicrobiana; e os resultados compilados são muito promissores e poderão servir de ponto de partida para estudos futuros. 


\section{REVISÃO TEÓRICA}

Os meios de culturas são compreendidos como sendo preparações químicas que, em sua formulação, possuem os nutrientes necessários à multiplicação de microrganismos, tendo, como objetivo, sua análise e estudo (PROLAB, 2014). Os meios de cultura têm diferentes funções e sua utilização é de notável importância no cultivo para posterior identificação dos microrganismos capazes de provocar doenças, como alergias ou infecções em seres humanos, revelar possíveis contaminações da água ou de alimentos, identificando as bactérias patogênicas ou não patogênicas (TORTORA et al., 2012). São classificados como sólido, semissólido e liquido. A quantidade de nutrientes e p.H podem variar dependendo da espécie estudada, isso devido à vasta gama de microrganismos existentes, mas todos os meios são nutritivos e possibilitam o crescimento dos microrganismos seletivamente ou não (PROLAB, 2014).

Baseado nesses critérios, os laboratórios e/ou unidades de produção de meios de cultura precisam atentar às normas e procedimentos de produção, uma vez que o meio solicitado pelo cliente deve estar livre de qualquer contaminante que possa alterar as suas análises (PROLAB, 2014).

Uma das preocupações para um meio de cultura livre de contaminações é a embalagem, que deve estar previamente esterilizada. Na maioria das vezes essas embalagens vêm de fábrica estéreis e passam por algum processo de esterilização (álcool, autoclave, etc) no próprio laboratório, porém os riscos de contaminação durante a manipulação devem ser considerados, já que podem ocorrer erros de manipulação e até mesmo contaminação externas.

Reagentes e meios de cultura são produzidos e armazenados em vidros ou frascos PET (politereftalato de etileno). O PET é o recipiente que tem estado cada vez mais presente no cotidiano das pessoas. Isso se deve a algumas propriedades desse material, como leveza, atoxicidade, durabilidade, baixo custo, capacidade de ser reciclado, moldado e substituir produtos feitos de metais, madeira, vidro, papel, entre outros. Além disso, apresenta uma variedade de aplicações, desde plásticos rígidos altamente cristalinos a polímeros dúcteis (FARIA, 2010).

O crescente uso do PET e seu descarte incorreto têm provocado uma série de danos ao meio ambiente, uma vez que, os mesmos são produzidos a partir de polímeros sintéticos 
convencionais, bastante resistentes ao ataque de microrganismos, e, portanto, levam mais tempo para se degradarem, contribuindo assim para o aumento da quantidade de resíduos plásticos presentes no meio ambiente (CASARIN et al. 2013).

\section{METODOLOGIA}

Foram realizados 3 experimentos, com frascos PET transparente e tampa com lacre (frascos tipo pet), volume final de 100 mililitros (ml). Cada frasco recebeu 1 tipo de tratamento, que foram separados por:

a) Controle negativo (água): a água foi designada como controle negativo, divergindo do convencional, pois era esperado o crescimento de microrganismos nos frascos tratados por ela.

b) Controle positivo (álcool 70\%): o álcool 70\% foi usado como controle positivo, porque apresenta ação antimicrobiana e o esperado era que não houvesse crescimento de microrganismos nos frascos tratados com ele.

c) Fase aquosa pura (FA)

d) Concentrações de fase oleosa (FO) misturada a álcool $70 \%$.

Foram 5 intervalos de tempo de recebimento da solução de FO e álcool 70\%, FA, álcool $70 \%$ e água. O procedimento para a esterilização dos frascos foi o mesmo em todos os tratamentos:

- Foram colocados $100 \mathrm{ml}$ da solução de tratamento (incluindo controles) em cada frasco, agitou levemente por duas vezes para que a solução entrasse em contato com a tampa, após essa agitação a solução foi retirada seguindo o tempo estipulado para o tratamento e frasco.
A) controle negativo 
Água (T0 - menor tempo possível de contato - cerca de 15 segundos): foram colocados $100 \mathrm{ml}$ de água de torneira, agitou levemente por duas vezes para que a água também entrasse em contato com a tampa; após essa agitação a água foi imediatamente retirada do frasco.

Água 60 minutos: foram colocados $100 \mathrm{ml}$ de água de torneira, agitou levemente por duas vezes para que a água também entrasse em contato com a tampa e após essa agitação a água foi deixada no frasco por 60 minutos; após esse período a mesma foi retirada do frasco.

Água 360 minutos: foram colocados $100 \mathrm{ml}$ de água de torneira, agitou levemente por duas vezes para que a água também entrasse em contato com a tampa e após essa agitação a água foi deixada no frasco por 6 horas; após esse período a mesma foi retirada do frasco.

Água 720 minutos: foram colocados $100 \mathrm{ml}$ de água de torneira, agitou levemente por duas vezes para que a água também entrasse em contato com a tampa; após essa agitação a agua foi deixada no frasco por 12 horas, e depois desse período a mesma foi retirada do frasco.

Água 1440 minutos: foram colocados $100 \mathrm{ml}$ de água de torneira, agitou levemente por duas vezes para que a água também entrasse em contato com a tampa e depois dessa agitação a água foi deixada no frasco por 24 horas; após esse período a mesma foi retirada do frasco.

Os frascos e tampas permaneceram 14 dias com a abertura voltada para cima e 14 dias com a abertura virada para baixo, para retirada do excesso de solução (controles ou solução antimicrobiana).

Neste trabalho, a água foi denominada como controle negativo, seguindo o mesmo período de tempo que os demais tratamentos realizados.

Controle positivo - álcool $70 \%$.

Fase aquosa (FA): foi utilizado um lote de antimicrobiano com atividade comprovada em testes realizados em S. aureus e Salmonella.

A fase oleosa utilizada foi de um lote com alta eficiência comprovada em testes realizados com S. aureus e Salmonella.

- Fase oleosa 1\%: foi feito $500 \mathrm{ml}$ de solução - $5 \mathrm{ml}$ de fase oleosa e $495 \mathrm{ml}$ de álcool $70 \%$. 
- Fase oleosa 5\% misturado a 95\% de álcool $70 \%$.

- Fase oleosa $10 \%$ misturado a $90 \%$ de álcool $70 \%$.

- Fase oleosa $15 \%$ misturado a $85 \%$ de álcool $70 \%$.

- Fase oleosa $20 \%$ misturado a $80 \%$ de álcool $70 \%$.

O álcool 70\% foi escolhido para diluir a fase oleosa, pois segundo Ribeiro et al., (2015), o álcool $70 \%(\mathrm{p} / \mathrm{v})$ auxilia na eliminação de microrganismos vegetativos, vírus, fungos, microbactérias.

As tampas entraram em contato com as soluções controle e soluções de esterilização no momento da agitação do frasco, e permaneceram 14 dias viradas para baixo, e o mesmo tempo viradas para cima. Após o período de esterilização dos frascos, foram colocados $20 \mathrm{ml}$ de meio de cultura liquido estéril; e o meio utilizado foi o Luria-Bertani (LB) 50\%. O meio LB foi utilizado por conter nutrientes essenciais para uma ampla gama de microrganismos mesmo com $50 \%$ dos nutrientes usados regularmente.

Foram realizados 3 experimentos, em datas diferentes, seguindo o mesmo protocolo de esterilização. Todas as manipulações dos frascos PET, foram realizados fora do fluxo laminar. Todas as manipulações foram realizadas em fluxo laminar devidamente limpo, para evitar riscos de contaminação. Após o período, cada frasco PET recebeu $20 \mathrm{ml}$ de meio LB 50\% caldo. Foram realizadas 6 avaliações, pelo período de 6 meses.

Para verificar a eficiência do antimicrobiano PHT 43.6, os frascos PET tratados e com meio de cultura LB 50\% foram levados para o fluxo laminar. Após serem abertos, uma pequena quantidade de meio foi coletado de cada frasco PET com o auxílio de uma alça, e imediatamente foi estriado em placa contendo meio 2XYT sólido. Após 24 horas de incubação, as placas foram observadas e avaliadas através de notas entre 0 e 4 , sendo nota 0 para crescimento nulo de microrganismo e 4 para a formação de tapetes. As avaliações foram realizadas após 15, 30, 45, 80, 110 e 200 dias após a incubação dos meios. 


\section{RESULTADOS E DISCUSSÃO}

Nos 3 testes realizados, os resultados mostraram que os controles positivo e negativo apresentaram crescimento microbiano em todos os testes esterilizados e em todas as combinações após 6 meses do início do primeiro experimento. No caso do controle negativo, foi utilizado a água para esterilizar os frascos PET. Na primeira semana após a colocação do meio de cultura nos frascos já era visível que ele estava turvo e no terceiro teste realizado, o resultado mostrou crescimento de microrganismos nas placas de petri (em meio 2XYT sólido).

O objetivo foi avaliar se os frascos tratados com água, álcool 70\%, fase aquosa, e concentrações de fase oleosa se diferenciavam entre si em relação ao crescimento microbiano. Para isso, o teste descrito em Materiais e Métodos foi o suficiente para responder ao objetivo. Quando o meio de cultura retirado dos frascos PET foi estriado em placa contendo meio sólido, era possível, após 24 horas, observar se havia crescimento ou não de microrganismos; por isso não foram realizados testes de espalhamento para conferir quantidade e tipos de colônias.

No controle positivo, álcool 70\%, houve crescimento de fungos após 15 dias da colocação do meio. A princípio, especulou-se a possibilidade de ser contaminação pelo ar ou manuseio durante o processo, mas, após 2 meses era possível observar o crescimento de microrganismos nos frascos que foram esterilizados com álcool $70 \%$. Visualmente o meio havia turvado, e a contaminação foi comprovada através dos testes realizados em placas contendo meio 2 XYT sólido, pois apresentaram crescimento de microrganismos.

A primeira avaliação foi realizada 15 dias após a colocação do meio de cultura nos frascos PET; as avaliações não seguiram um intervalo de tempo regular, uma vez que os experimentos foram realizados em datas diferentes.

O segundo teste apresentaram resultados que reforçaram os primeiros experimentos. Houve uma contaminação por fungo a partir da primeira semana no frasco tratado com Álcool 70\% 12 horas, na última avaliação realizada, todos os frascos tratados com Álcool 70\%, apresentaram crescimento de microrganismos.

Os resultados se repetem quando comparados aos testes 1 e 2, com crescimento de microrganismos nos controles negativos e positivos. Nos demais tratamentos o composto o 
antimicrobiano evitou o desenvolvimento de microrganismo. Foi possível observar que houve crescimento de microrganismos no teste realizado no frasco tratado com fase aquosa (FA) T0, mas, como o resultado não se repetiu, concluiu-se que foi contaminação do teste realizado ao lado do quadrante deste frasco.

Os resultados foram promissores, indicando que mesmo após 6 meses de experimento os frascos tratados mantiveram o meio de cultura sem contaminantes. Os testes realizados mantiveram um padrão de resultados onde o controle negativo apresentava contaminação 24 horas após a colocação do meio de cultura, pois o meio ficava turvo, e após 15 dias esse crescimento era mostrado nos testes em placas de petri. O controle positivo começou a presentar contaminações e crescimento de fungos após 1 semana. Os demais tratamentos não tiveram crescimento de microrganismos.

Para evitar contaminações, são usados muitos processos de reciclagem de limpeza profunda, também chamados de superlimpeza em frascos PET e/ou embalagens de uso laboratorial. Estes processos envolvem muitas etapas de limpeza (tratamento a vácuo, tratamento com altas temperaturas, limpeza profunda da superfície exposta, etc.) para a eliminação de substâncias indesejáveis, eventualmente advindas do pós-consumo do PET (FORMIGONI \& CAMPOS, 2012)

A FDA tem metodologias para testes dos materiais reciclados obtidos de processos comerciais e destinados à aplicações em que haja contato com alimentos, os chamados “Challenge Tests (FDA 1992; 1995; 2016). Eles determinam a padronização das concentrações de contaminantes, com o estabelecimento de valores mínimos aceitáveis de exposição (FDA, 2016), sendo suficiente, caso aprovada, para a aplicação desses materiais em embalagens com contato direto com alimentos (FDA, 2016).

Em qualquer técnica, a maior preocupação é a deformação do material e resíduos nocivos à saúde no PET, essa preocupação levou Faria (2010), a gerar uma patente de um equipamento caracterizado por sanitizar frascos PET, que compreende um reservatório de sanitizante, um reservatório de água, um esterilizador de água, um trocador de calor, dreno para descarte de água, bicos aspersores, sendo um de sanitizante e outro de água, e dispositivos de controle de tempo e temperatura; mas não há relatos da eficiência deste equipamento na esterilização dos frascos. 
Isoldi et al., (2002) usou uma técnica que expôs o PET a feixes de radiação ionizante, e nestes estudos houve uma mudança de conformação do material quando exposto várias vezes à radiação. Os resultados são promissores, como uma nova alternativa para a reciclagem dos PET, porém, apresentam alguns pontos negativos, pois o PET pode se tornar frágil com doses errôneas de radiação, e o uso constante da mesma pode alterar suas propriedades de forma a prejudicar a esterilização do material e inviabilizar a sua reutilização.

Araújo (2010), realizou estudos utilizando timol e carvacrol e concluiu que ambos apresentam atividades semelhantes frente à diversas bactérias; no entanto, já foram constatadas diferenças na ação destes elementos contra espécies de bactérias Gram-positivas e Gramnegativas. Mesmo diante da eficiência comprovada não foram realizados testes de esterilização usando esses compostos em embalagens, divergindo do nosso trabalho.

Todas as pesquisas relacionadas ao uso da radiação, mostram que essa técnica é extremamente eficiente. Mas apresentam alguns pontos negativos, como o alto custo, e possíveis resíduos que podem ficar impregnados nos materiais. E isso demanda o uso de novas tecnologias para essa finalidade. Em nossos testes com o antimicrobiano, obtivemos um resultado positivo, já que não observamos alteração no material plástico que proporciona a esterilização do frasco PET.

\section{CONCLUSÃO}

As indústrias de alimentos e bebidas buscam constantemente novas tecnologias para evitar a contaminação e ou crescimento de microrganismos em seus produtos e um composto natural, que atua nessa frente é muito atrativo para as mesmas. O composto PHT 43.6 é um antimicrobiano com grande potencial mercadológico. Em diferentes testes foi comprovado a sua eficiência na inibição de microrganismos. Mediante esses resultados positivos surgiram indagações sobre sua eficiência na esterilização de frascos e os resultados dos testes apresentados mostraram que o composto é muito eficiente na esterilização de frascos PET. Apesar dos resultados serem muito positivos e promissores, durante a realização dos testes foram surgindo algumas dúvidas e problemas no desenvolvimento dos protocolos para conseguir efetivamente colocar o composto PHT no mercado. Essas dificuldades serão sanadas realizando novos testes e novos protocolos. 


\section{REFERÊNCIAS}

ABIPET - Censo da Reciclagem de PET no Brasil. 2012. Acessado em 16 de Junho de 2017.

ARAUJO, R. C. Óleos essenciais de plantas brasileiras como manipuladores da fermentação ruminal in vitro. Tese apresentada à Universidade de São Paulo Escola Superior de Agricultura “Luiz de Queiroz”, Piracicaba, 181p, 2010.

ARAUJO, L. S.; ARAUJO, R. S.; SERRA, J. L. Composição química e susceptibilidade do óleo essencial de orégano (Oreganun vulgare) frente as cepas de E. coli, S. aureus e $S$. choleraesuis. Centro de Pesquisa e desenvolvimento de Alimentos. v. 33, n. 1 (2015).

BELÉM, M.A.F. 2000. Application of biotecnology in the product development of nutraceuticals in Canada. Trends in Food Science and Technology, 10:101-106.

CASARIN, S. A., AGNELli, J. A. M., MALMONGE, S. M., \& ROSARIO, F. (2013). Blendas PHB/copoliésteres biodegradáveis: biodegradação em solo. Polímeros: Ciência e Tecnologia, 23(1), 115-122.

ENZIME MARKET. https://www.researchgate.net/figure/236925667_fig1_Global-enzymeindustry-market-in-the-years-2011-and-2016. 2016. Acesso em 05 de abril de 2017.

FARIA, J. de A. F. 2010. Sistema de esterilização de embalagem. http://repositorio.unicamp.br/jspui/handle/REPOSIP/85081. Acessado em 24 de março de 2017.

FDA - FOOD AND DRUG ADMINISTRATION. Recycled plastics in food packaging. 2016. Disponível em: http://vm.cfsan.fda.gov/ dms/ opa-recy.html. Acessado em: 25 de Janeiro 2017.

FORMIGONI, A.; CAMPOS, I. P. A. Reciclagem de PET no Brasil. http://www.aedb.br/seget/arquivos/artigos07/1200_1200_ARTIGO\%2020RECICLAGEM\%2 0DE\%20PET\%20NO\%20BRASIL.pdf. Resumo. Universidade Estadual Paulista - UNESP. 2012. Acessado em 10 de março de 2017. 
ISOLDI, A.B.G.; ROSARIO, S.C.; ANDRADE e SILVA, L.G. Estudo do efeito da dose de radioesterilização sobre as propriedades do poli (tereftalato de etileno) - PET reciclado. Revista Brasileira de Pesquisa e Desenvolvimento, v. 4, n. 3, p. 1665-1668, 2002.

KALAPOTHAKIS, E. \& VICTORIA, J. M. N. Óleo de girassol (Helianthus annuus) modificado enzimaticamente, processo de obtenção e uso dos seus derivados como antimicrobianos. http://google.com/patents/WO2014097218A1?cl=ar. Belo Horizonte, MG, 2012. Acessado em 01 de março de 2017.

LIN, E. S.; WANG, C. C.; SUNG, S. C. Cultivating conditions influence lipase production by the edible Basidiomycete Antrodia cinnamomea in submerged culture. Enzyme and Microbial Technology, v. 39, n. 1, p. 98-102, 2005.

RODRIGUES, A. A. Atividade antimicrobiana e produção de enzimas de interesse biotecnológico de bactérias isoladas de diferentes habitats. Dissertação. Universidade Federal de Goiás. Goiânia - GO, 2009. Acessado em 07 de março de 2017.

TORTORA G. J., BERDELL, C. L. C., FUNKE, R. Microbiologia - 12 $2^{\mathrm{a}}$ Edição. Artmed. 2012. 